\title{
Reflections on 40 Years of Applied Economics Research on Agriculture and Water Quality
}

\section{Marc Ribaudo, and James Shortle $\odot$}

\begin{abstract}
Reducing agricultural nonpoint pollution has been an environmental policy issue since the early 1980s. We discuss the evolution and results of federal and state policy, the contributions of applied economic research to improving the effectiveness and efficiency of water pollution control policies for agriculture, elements of policy reforms that are consistent with the Clean Water Act, and the outlook for needed policy innovation.
\end{abstract}

Key words: Agriculture, Nonpoint pollution, Water pollution policy, Applied economic research, Policy research

The NAREA Award for Outstanding Public Service through Economics honors and recognizes economists who have applied agricultural, environmental, consumer, resource, or community development economics to solve an important problem and improve the welfare of society. This award was presented to James Shortle and Marc Ribaudo at the 2018 Annual Meeting for their research and outreach on policies for addressing water quality impacts of agriculture. The following invited article outlines their views on and contributions to improving the effectiveness and efficiency of water pollution control policies for agriculture.

Agricultural nonpoint water pollution began to be recognized as a significant and pervasive cause of water quality problems in the United States at about the time we started our careers in the early 1980s. It was perfect timing for us. We had learned the concepts and tools that environmental economics provides for policy evaluation and policy design from our academic training and were eager to put them to use to solve agricultural externalities. Our careers have intersected on these issues for nearly 40 years! But our platforms were very different, with Marc at the U.S. Department of Agriculture (USDA) Economic Research Service and Jim being an academic. Differences in platforms and specific research interests led to big differences in the questions we pursued. Marc's early work focused on the water quality benefits of USDA

\footnotetext{
Marc Ribaudo, USDA, Economic Research Service (Retired), Garner, North Carolina. James Shortle, Pennsylvania State University, Department of Agricultural Economics, Sociology, and Education, University Park, Pennsylvania. Correspondence: James Shortle, Environment and Natural Resources Institute, 111 Ferguson Building, Penn State University, University Park, PA 16802, Email: jshortle@psu.edu
}

Agricultural and Resource Economics Review 48/3 (December 2019) 519-530

(C) The Author(s) 2019. This is an Open Access article, distributed under the terms of the Creative Commons Attribution licence (http://creativecommons.org/licenses/by/4.0/), which permits unrestricted re-use, distribution, and reproduction in any medium, provided the original work is properly cited. 
conservation programs and contributed to a significant new understanding of the economics of these programs. Jim's work focused on the design of policy instruments for reducing agricultural nonpoint pollution. Frankly, there was much more interest in Marc's work than Jim's. Water quality policy makers at the time were not interested in new regulatory approaches to address water pollution from agriculture. They were interested in the role that traditional agricultural conservation programs could play in addressing these problems, and Marc's work demonstrating the water quality benefits of these programs provided empirical support for this approach.

In the early 1980 s and for many years after, the traditional voluntary conservation policy model, as opposed to explicit pollution control policies, was the primary approach policy makers took to agricultural nonpoint pollution control. The underlying belief was that moral suasion combined with technical and financial assistance to encourage and facilitate the adoption of Best Management Practices (BMPs) ${ }^{1}$ was the best way forward. While these efforts put a lot of conservation practices on the ground, they generally did not produce noticeable improvements in water quality. Nearly 40 years later, agriculture remains a major cause of unmet water goals in the U.S. (EPA 2017). Finding solutions to this problem, from our differing platforms, led to convergence in our work.

\section{Agriculture and Water Quality}

Water pollution control has been an area of significant state and federal regulation as well as the focus of enormous public and private spending for decades (Keiser and Shapiro 2018). Yet water quality problems remain. Contemporary headline-grabbing examples include the large hypoxic zone in the Gulf of Mexico, eutrophication of the Chesapeake Bay, and massive algae blooms in Lake Erie. But there is much more to the nation's water ongoing quality problem than these high-profile cases. For example, a recent U.S. Environmental Protection Agency (EPA) assessment based on statistical sampling finds that 46 percent of U.S. rivers and streams are in poor biological condition, 25 percent are in fair condition, and only 28 percent are in good condition (EPA 2016). For regulatory purposes, a key indicator of water quality problems is the number of impaired waters. Section 303d of the 1972 Clean Water Act (CWA) requires U.S. states to establish water quality standards for specific water bodies and to list as impaired waters those that do not meet the designated standards. The CWA requires states to develop plans called Total Maximum Daily Loads (TMDLs) for such waters. Impairments of

\footnotetext{
1 Agricultural BMPs refer to farming practices that reduce the amount of sediment, fertilizer, animal wastes, and other pollutants entering water resources from agricultural activities.
} 
rivers and streams, lakes, ponds, and reservoirs, bays and estuaries, and wetlands are numerous and widespread (EPA 2017).

Of particular importance to the condition of the nation's waters is nutrient pollution, which the EPA describes as "one of America's most widespread, costly and challenging environmental problems" (EPA 2009). Nutrients (nitrogen and phosphorous) are the cause of many of the high-profile water quality problems in the U.S. - the Gulf Dead Zone, eutrophication of the Chesapeake Bay, and algae blooms in Lake Erie. But they are also pervasive causes of smaller-scale problems. EPA's statistically based water resource assessments find nitrogen and/or phosphorous to be the leading stressors of rivers and streams, lakes, and coastal waters (EPA 2017).

Agriculture figures prominently in the nation's ongoing water quality problems. The EPA National Water Quality Inventory cited above lists agricultural nonpoint source (NPS) pollution as the leading cause of water quality impairments on surveyed rivers and streams, the third-largest cause for lakes, the second-largest for wetlands, and a major contributor to contamination of estuaries and groundwater (EPA 2017). The nation's nutrient pollution problems are to a very large degree the result of the largescale direct (fertilizer) and indirect (animal feed) use of nitrogen and phosphorous in agricultural production (Shortle and Horan 2017).

\section{The Need for Policy Innovation}

Ongoing water quality problems and agriculture's large role in them is in large degree a consequence of the nation's water quality policy architecture as structured by the 1972 CWA (Shortle et al. 2012, Shortle 2017). The CWA nationalized the control of municipal and industrial point sources of water pollution and led to the establishment of strict regulations that have been highly effective in reducing pollution from point sources. On the other hand, pollution from nonpoint sources is specifically exempt from such controls. The CWA instead directed the states to take primary responsibility for the management of agricultural NPS pollution and directed the USDA to provide technical and financial assistance for reducing agricultural NPS pollution. In contrast to the federal approach to point sources, states have largely pursued voluntary compliance programs that encourage and facilitate adoption of pollution control practices (Shortle et al. 2012). While the states have legal responsibility for agricultural NPS pollution, the most significant public investments in controlling the problem come from U.S. Department of Agriculture conservation programs authorized by federal farm legislation (Shortle and Uetake, 2015). The NPS exemption from federal regulation under the CWA, the legacy of federal conservation programs for managing agricultural land use, and a common belief that conventional conservation practices provided technological solutions with significant private benefits all contributed to a heavy focus on voluntary approaches that offer financial and technical assistance to farmers to 
encourage the adoption of conservation practices for reducing NPS pollution (Shortle and Uetake 2015).

State polices and federal subsidies for agricultural NPS have not done what is required to meet established water quality goals. This conclusion is apparent from the condition of the nation's waters and the role of agriculture as a leading stressor. This conclusion is also supported by specific assessment of these programs (e.g., Diebel et al. 2008, Arbuckle 2013). The voluntary approach has generally not led to sufficient aggregation of conservation efforts in impaired watersheds to produce needed improvements in water quality.

Limitations of the current policy architecture are well illustrated by Lake Erie (International Joint Commission 2014; Shortle 2017). Prior to the 1970s, excess nutrient loads and severe eutrophication greatly reduced the lake's value for fishing, water supply, and aesthetics. Phosphorous from municipal sewage treatment plants was the leading cause. Regulations and investments beginning in the 1970s reduced phosphorous loads by more than half by the mid-1980s. However, nutrient problems returned in the early 2000s and have become more severe since, punctuated by widespread harmful algal blooms. While a variety of factors contributed to the relapse, increased dissolved $\mathrm{P}$ (a highly potent form) from nonpoint sources, particularly agriculture, plays a leading role.

Ongoing water pollution is one important problem resulting from the existing policy architecture, but it is not the only one. Another is unnecessarily high costs from water quality protection and dissipation of the potential economic welfare gains from water pollution control. Water quality authorities compensate for the lax control of agricultural NPS by ratcheting up restrictions on point sources when water quality improvements are required, as these are more easily controlled under existing regulations. The result has been to push point source marginal abatement costs ever higher. Given that marginal abatement cost for point sources often substantially exceed those of agricultural NPS, the result is to substantially misallocate pollution abatement between point and nonpoint sources, increase the costs of water pollution control, and reduce the net benefits from water quality protection (U.S. Environmental Protection Agency 2001). Benefit-cost assessments of U.S. water quality pollution controls are generally not favorable and indicate that the incremental costs of additional point source controls exceed the benefits (Keiser, Kling, and Shapiro 2019; Olmstead 2010). Policy innovation is needed not only to improve the nation's waters but to improve the economic efficiency of water pollution control.

The substantial contemporary interest in reducing nutrient pollution in the Chesapeake Bay, Lake Erie, the Gulf of Mexico, and other places is creating new openings for economics to influence agricultural nonpoint pollution policy. The large role of agriculture in nutrient pollution means that water quality authorities must implement policies for agriculture that are more effective than those that have been pursued in the past. 


\section{Policy options for reducing NPS}

How can NPS from agriculture be reduced within the current mostly regulatorylite policy architecture? The need for policy innovation brings with it concerns for getting the most out of increasingly limited budgets for financial and technical assistance for BMP adoption in agriculture along with concerns for the impacts of stricter controls on the agricultural economy. Simple concepts and principles long familiar to environmental economists and tools to implement them have become important to water quality managers. For example, it was not long ago that spatial targeting of resources for costeffective pollution control was an unwelcome concept in water quality management. It is now a recognized need in places where managers need to utilize scarce resources to achieve water quality goals.

Perhaps the large challenge for economists in this domain will be to facilitate a paradigm shift from the pay-the-polluter (PTP) model that currently dominates agricultural nonpoint pollution control policy to approaches that are more economically efficient. Key elements of modest reforms in this direction are (Shortle et al. 2012): (i) tying instruments to explicit, measurable performance goals, rather than to BMPs; (ii) improving instrument design (better payment mechanisms and better targeting); (iii) improving integration of water quality programs with farm commodity and other farm programs to increase the resources available for water quality protection and reduce perverse incentives; and (iv) adding modest polluterpays (PP) reforms to the policy toolkit where possible or necessary. The modifications could facilitate a transition from the current fiscally unsustainable PTP approach to a fiscally sustainable PP paradigm, given that high political transactions costs associated with fundamental institutional change reinforce the status quo. While the undesirable characteristics of subsidies for environmental improvement are not eliminated during the transition (incentives for landowners to continue production when they otherwise might not), their impacts would be reduced.

Opportunities exist for increasing the cost-effectiveness of conservation programs offered mainly by the USDA. It spends several billion dollars annually in financial and technical assistance to help farmers improve resource management on farms. However, improved water quality is just one of many goals addressed by these programs. And since these programs are voluntary, farmers get to choose which goals to address (supply driven environmental quality rather than demand driven). Most farmers, understandably, seem to be more concerned with on-farm issues that directly affect profitability rather than water quality concerns that are felt off the farm (downstream).

Cost-effectiveness is an important determinant of how much conservation programs accomplish in terms of environmental services such as water quality. Research suggests that the cost-effectiveness of conservation programs can vary widely depending on how much is paid to which farmers 
for taking what actions (Shortle et al. 2012). Given that most USDA conservation programs are subject to budget constraints, the environmental gain that a program can leverage is maximized when payments are just large enough to encourage adoption by those farmers who can provide the greatest environmental benefits at the least cost. Key elements for increasing the costeffectiveness of conservation programs include switching from an incentive model in which farmers are paid to implement pollution-reducing farming practices to one in which payments are received for actual or expected improvements in water quality (pay-for-performance), switching from a firstcome, first-served process to a resource allocation model that targets limited resources to high-priority problems in high-priority places (targeting) and utilizing payment mechanisms that minimize payments in excess of farmers' willingness to accept (Shortle et al. 2012; Ribaudo 2017).

\section{TARGETING}

Focusing conservation efforts on regions with high levels of impairments (potentially high benefits), fields within watersheds that contribute a disproportionate amount of pollutants, and practices that tend to be most cost-effective in reducing pollution would be a formula for increasing the overall cost-effectiveness of a program (Babcock et al. 1997). In many cases, the confluence of vulnerable resources and environmentally risky practices produces situations in which a large share of pollution originates on a relatively small number of farms and fields (Ribaudo 1989; Nowak, Bowen, and Cabot 2006; Diebel et al. 2008). In the Mississippi River Basin, for example, 10 percent of cropland is estimated to contribute 30 percent of the entire nitrogen load from cultivated cropland to the Gulf of Mexico (White et al. 2014). Targeting these settings would enhance program costeffectiveness.

Some USDA programs have recognized the benefits of targeting. The Rural Clean Waters Program (1980s) and the President's Water Quality Initiative (1990s) are two examples. However, targeting has raised equity issues within programs, where farmers not in a targeted situation may believe they are at a disadvantage in obtaining program benefits. In response to such complaints Congress forbade geographic targeting within the EQIP program, but targeting is still possible in the way individual states allocate program funds.

Effective targeting requires that monitoring data, models, or other measurement tools identify those settings where large environmental gains can be attained at relatively low cost. From a cost-effectiveness standpoint, successful targeting also requires the most cost-effective practices to be employed on those farms that can reduce pollutants at the lowest cost. Achieving this is much more difficult when programs are voluntary, however. Farmers who can provide the most cost-effective control may not enroll in targeted programs or may want to address other issues on their farms that more directly affect their net returns. 


\section{ADDITIONALITY}

Improvements in environmental quality can be attributed to conservation payments only if farmers would not have adopted the practice without the payment. Such practices are said to be additional. Additionality depends on the characteristics of conservation practices. Practices with high adoption costs relative to private benefits (directly realized by the farmer) or those that are difficult to reverse are more likely to be additional (require conservation payment to be adopted) than practices with high private benefits relative to adoption costs (Claassen, Duquette, and Smith 2018). Conservation tillage is an example of a practice with generally high private benefits that many farmers have adopted without any financial assistance from government programs. Providing financial assistance for conservation tillage when it would have been adopted anyway could reduce overall program efficiency. On the other hand, structural and off-field practices such as fencing, terraces, and vegetative buffers have high implementation costs and/or low private benefits. Such practices have been found to be mostly additional (Claassen, Duquette, and Smith 2018).

The cost-effectiveness of existing conservation programs could be improved if information on additionality were considered in determining eligibility for financial support and support rates. Predicting which farmers need assistance to adopt a practice and which do not is difficult due to asymmetric information, differences in local resource conditions, and differences in farmer ability and attitude toward environmental protection. One approach could be to establish a practice baseline in a region that reflects local non-additional practices (practices farmers tend to adopt on their own). Practices eligible for financial assistance could be limited to those believed to be most additional.

\section{AUCTIONS}

When farmers have more information about practice implementation costs than the buyers (asymmetric information), the potential exists for them to receive a payment in excess of what is actually needed when a single "price" is offered for the adoption of that practice. This reduces overall program cost-effectiveness. Auctions are a mechanism that can counter this behavior. When there is one buyer (USDA) and many sellers (farmers), auctions can facilitate competition between participants that can improve program cost-effectiveness (Hellerstein, Higgins, and Roberts 2015).

Specifically, farmers simultaneously offer (or "competitively bid") a level of performance (components in a contract) and their required level of compensation. The managing agency then selects the offers that provide the most environmental benefit at least cost until the budget or acreage goal is exhausted. Farmers who seek "excessive profit" from their offer risk being outcompeted by other bidders. Accordingly, farmers have an incentive to make an offer that is closer to their willingness to accept (generally an amount that just covers costs) than they might otherwise, thus increasing their chances of being awarded a contract. For auctions to be effective, costs 
and benefits of ecosystem services should vary across potential participants and there should be enough potential sellers to spur competition (increasing the likelihood that high bids will not be accepted).

Auctions have been successfully used in the general sign-up of the Conservation Reserve Program. In EQIP, bidding down (taking a lower costshare) is forbidden by Congress, due to concerns that small or resourcelimited farmers cannot compete with larger farms (based on experience when bidding down was allowed). The only option for competing would be in terms of the level of environmental services that could be provided. A bundle of practices with high environmental benefits would be accepted before a contract with the same cost but with lower environmental benefits. This type of bidding also increases cost-effectiveness, although maybe not to the degree it would if costs were also biddable.

\section{PERFORMANCE-BASED PAYMENTS}

Even with design features such as targeting and auctions to promote costeffectiveness, there is still the issue of attracting into the program those farmers who can provide the most environmental gain at the least cost. For example, if farmers who can provide the most pollution reduction at the lowest cost do not apply for a contract in a program that uses an auction, then an opportunity for getting the most out of program resources is lost. Without adequate compensation, farmers motivated primarily by profit likely have little incentive to voluntarily undertake actions that provide few benefits to them (Claassen, Cattaneo, and Johansson 2008). One way to address this issue is to base financial assistance on environmental performance rather than on a portion of implementation cost.

In general, paying for performance (e.g., amount of nutrient loss to water reduced) is more cost-effective than basing payments on practice costs (Ribaudo, Horan, and Smith 1999; Ferraro and Simpson 2002; Savage and Ribaudo 2016). Importantly, those farmers who can provide the most abatement at the lowest cost have the largest economic incentive to act (the program is self-targeting). This means that farmers who may not have traditionally participated in conservation programs might have a strong incentive to do so. In addition, performance-based payments could provide greater flexibility in how a particular environmental service is produced. Practice-based payments tend to limit choice to those practices that are costshared, while performance-based policies award innovations that lower costs. Savage and Ribaudo (2016) estimated that payments based on nutrient reductions in the Chesapeake Bay Watershed would achieve a water quality goal at a much lower cost than payments based on practice costs, even with location-based targeting. Field-level measurement tools for estimating environmental performance are needed with performance-based policies. Such tools, including the NRCS's Nutrient Tracking Tool, are being developed and are currently being used in water quality trading (a pay-for-performance policy) and other programs. 
COORDINATING POINT AND NONPOINT-TRADING

Another avenue for improvement is through coordination of point and nonpoint source control. Trading is a fundamentally important innovation for water pollution control. In the U.S. and elsewhere, pollution control policies have historically addressed point and nonpoint pollution separately. Adverse trends in water quality and high water quality protection costs show that this separation is harmful to the achievement of water quality objectives and to the efficiency of water quality protection. Watershed-based approaches recommended by water science call for integrated treatment. One important opening for research in this area came with the implementation of EPA's TMDL program in the late 1990s. Section 303d of the CWA requires states to develop total maximum daily loads (TMDLs) for water bodies that did not meet designated uses even with point source effluent limit compliance. A TMDL establishes the maximum amount of a pollutant that a water body can receive and still meet water quality standards. It also specifies how the overall pollutant load is allocated among the various sources, including nonpoint sources.

The primary purpose of pollution trading with agricultural sources in the U.S. has been to avoid high control costs for regulated point sources. Several programs have been implemented, but the expected savings have generally not emerged. Poor program design and lack of necessary economic conditions for success appear to be primary factors (Ribaudo and Gottlieb 2011; Fisher-Vanden and Olmstead 2013). However, the fundamental merit of integrative trading for rationalizing and improving the efficiency of water quality protection is seen in some recent experiments with baseline-andcredit WQT programs. These programs, designed to substitute low-cost nonpoint pollution controls for expensive point source controls, are promising if not completely proven (Shortle and Horan 2013; Shortle 2013). These experiments include phosphorus programs on the South Nation River in Ontario, Canada, and the Little Miami River in Ohio, and nitrogen and phosphorous trading programs for the Susquehanna River in Pennsylvania. A point-nonpoint trading program has recently been implemented for the Ohio River Basin in the U.S., and there is significant interest in point-nonpoint programs to manage nutrient pollution in the Baltic Sea and elsewhere.

\section{Looking Forward}

The agricultural nonpoint source pollution control policy innovations proposed above would not require a large investment in government funds but would facilitate greater efficiency and effectiveness of resource devoted to the problem. So what does it take to induce change? If the recent past is any example, change is mostly driven by perceived environmental crises and the courts. Weather-related hog waste lagoon failures and outbreaks of pfiesteria in North Carolina and the Chesapeake Bay were major factors in the 
implementation of new Clean Water Act rules for concentrated animal feeding operations. The significant increase in the use of the TMDL provisions of the Clean Water Act was the result of lawsuits by environmental groups pushing for better water quality protection. Several states have implemented requirements for nutrient management plans due to nutrient-related water quality problems. Current headline issues such as nutrient enrichment of western Lake Erie and the Gulf of Mexico Dead Zone may provide the additional push for more effective agricultural nonpoint source control policies. Policy makers contending with increasingly limited budgets for technical and financial assistance for agricultural BMPs, and for regulatory monitoring and enforcement, and who have a growing understanding of the high cost of traditional regulatory approaches will have incentives to seek out innovative approaches. Given the high social costs from ongoing water quality damages and inefficient policy architectures, the economic value of applied economic research combined with effective policy education to discover and demonstrate the merits of better policies remains substantial.

\section{Acknowledgements}

This article is based on our presentations to the members of the Northeast Agricultural and Resource Economics Association on our joint receipt of the Association's 2018 "Award for Public Service through Economics." We are grateful to the Association and its member for this award. We would also like to acknowledge that we had many valued colleagues over the years who collaborated in the work upon which the award is based. In addition to Marc, Jim is especially appreciative of his colleagues Rick Horan and David Abler.

\section{Financial Disclosure}

This research received no specific grant from any funding agency, commercial or not-for-profit sectors.

\section{Conflicts of Interest}

None.

\section{References}

Arbuckle, J.G. 2013. "Farmer Support for Extending Conservation Compliance Beyond Soil Erosion: Evidence from Iowa." Journal of Soil and Water Conservation 68(2): 99-109.

Babcock, B.A., P.G. Lakshminarayan, J. Wu, and D. Zilberman. 1997. "Targeting Tools for the Purchase of Environmental Amenities." Land Economics 73(3): 325-339.

Claassen, R., A. Cattaneo, and R. Johansson. 2008. "Cost-effective Design of AgriEnvironmental Payment Programs: U.S. Experience in Theory and Practice." Ecological Economics 65(4): 737-752. 
Claassen, R., E. Duquette, and D. Smith. 2018. “Additionality in U.S. Agricultural Conservation Programs." Land Economics 94(1): 19-35.

Diebel, M.W., J.T. Maxted, D.M. Robertson, S. Han, and M.J. Vander Zanden. 2008. “Landscape Planning for Agricultural Nonpoint Source Pollution Reduction I: A Geographical Allocation Framework," Environmental Management 42: 789-802.

Ferraro, P.J., and R.D. Simpson. 2002. "The Cost-effectiveness of Conservation Payments." Land Economics 78(3): 339-353.

Fisher-Vanden, K., and S. Olmstead. 2013. "Moving Pollution Trading from Air to Water: Potential, Problems, and Prognosis." Journal of Economic Perspectives 27(1): 147-171.

Hellerstein, D., N.A. Higgins, and M. Roberts. 2015. "Options for Improving Conservation Programs: Insights from Auction Theory and Economic Experiments." Amber Waves (February).

International Joint Commission. 2014. A Balanced Diet for Lake Erie: Reducing Phosphorus Loadings and Harmful Algal Blooms. Report of the Lake Erie Ecosystem Priority. Available at http://www.ijc.org/files/publications/2014\%20IJC\%20LEEP\%20REPORT. pdf.

Keiser, D. A., C.L. Kling, and J.S. Shapiro. 2019. "The Low but Uncertain Measured Benefits of US Water Quality Policy." Proceedings of the National Academy of Sciences 116(12): 5262-5269.

Keiser, D.A., and J.S. Shapiro. 2018. “Consequences of the Clean Water Act and the Demand for Water Quality." The Quarterly Journal of Economics 134(1): 349-396.

Nowak, P., S. Bowen, and P.E. Cabot. 2006. "Disproportionality as a Framework for Linking Social and Biophysical Systems," Sociology of Natural Resources 19(2): 153-173.

Olmstead, S.M. 2010. "The Economics of Water Quality." Review of Environmental Economics and Policy 4(1): 44-62.

Ribaudo, M.O. 1989. "Targeting the Conservation Reserve Program to Maximize Water Quality Benefits." Land Economics 65(4): 320-332.

Ribaudo, M. 2017. "Conservation Programs Can Accomplish More with Less by Improving Cost-Effectiveness," Choices Quarter 4. http://www.choicesmagazine.org/choices-magazine/ theme-articles/theme-overview-preserving-water-quality-challenges-and-opportunitiesin-policy-innovation/conservation-programs-can-accomplish-more-with-less-by-improvingcost-effectiveness.

Ribaudo, M.O., and J. Gottlieb. 2011. "Point-Nonpoint Trading-Can It Work? 1." JAWRA Journal of the American Water Resources Association 47(1): 5-14.

Ribaudo, M.O., R. Horan, and M.E. Smith, 1999, Economics of Water Quality Protection from Nonpoint Sources: Theory and Practice, Agricultural Economics Report, AER-782, Economic Research Service, U.S. Department of Agriculture, Washington, DC.

Savage, J., and M. Ribaudo. 2016. "Improving the Efficiency of Voluntary Water Quality Conservation Programs," Land Economics 92(1):148-166.

Shortle, J.S. 2013. "Economics and Environmental Markets: Lessons from Water-Quality Trading." Agricultural and Resource Economics Review 42(1): 57-74.

2017. "Economic Incentives for Water Quality Protection." Water Economics and Policy 3(2): 1771004.

Shortle, J.S., and R.D. Horan. 2013. "Policy Instruments for Water Quality Protection." Annual Review of Resource Economics 5(1): 111-138.

— 2017. "Nutrient Pollution: A Wicked Challenge for Economic Instruments." Water Economics and Policy, 3(02), 1650033.

Shortle, J.S., M. Ribaudo, R.D. Horan, and D. Blandford. 2012. "Reforming Agricultural Nonpoint Pollution Policy in an Increasingly Budget-Constrained Environment." Environmental Science \& Technology 46(3): 1316-1325.

Shortle, J.S., and T. Uetake. 2015. Agri-Environmental Policy in the United States. Paris: OECD. Available at http://www.oecd-ilibrary.org/agriculture-and-food/public-goods-andexternalities_5js08hwhg8mw-en. 
U.S. Environmental Protection Agency. 2001. The National Costs of the Total Maximum Daily Load Program. Washington, DC: U.S. Environmental Protection Agency, Office of Water, EPA-841-D-01-003, August.

2009. An Urgent Call to Action: Report of the State-EPA Nutrient Innovations Task Group. Washington, DC: U.S. Environmental Protection Agency, State-EPA Nutrient Innovations State Group, August. Available at https://www.epa.gov/sites/production/ files/documents/nitgreport.pdf.

2016. National Rivers and Streams Assessment 2008-2009: A Collaborative Survey. Washington, DC: U.S. Environmental Protection Agency, Office of Water and Office of Research and Development, EPA/841/R-16/007, March.

2017. National Water Quality Inventory. Available at https://www.epa.gov/waterdata/ national-water-quality-inventory-report-congress

White, M.J., C. Santhi, N. Kannan, J.G. Arnold, D. Marmel, L. Norfleet, P. Allen, M. DiLuzia, X. Wang, J. Atwood, E. Haney, and M. Vaughn Johnson. 2014. "Nutrient Delivery from the Mississippi River to the Gulf of Mexico and Effects of Cropland Conservation," Journal of Soil and Water Conservation 69(1): 26-40. 